\title{
Design of a ratiometric plasmonic biosensor for Herceptin detection in HER2-positive breast cancer
}

\author{
Neda Shahbazi ${ }^{1}$, Rouholah Zare-Dorabei ${ }^{1, *}$, Seyed Morteza Naghib ${ }^{2}$ \\ ${ }^{1}$ Research Laboratory of Spectrometry \& Micro and Nano Extraction, Department of Chemistry, Iran \\ University of Science and Technology, Tehran 16846-13114, Iran \\ ${ }^{2}$ Nanotechnology Department, School of Advanced Technologies, Iran University of Science and \\ Technology, Tehran, Iran \\ * Corresponding author: E-mail address: zaredorabei@iust.ac.ir ( Rouholah Zare-Dorabei ) \\ Tel: +98 2177240646 \& Fax: +98 2177491204
}

List of Tables and Figures for Supporting Information:

Table S1. Design table

Table S2. Analysis of variance (ANOVA) table

Figure S1. a) TEM images of AuNPs, b) FT-IR spectra of AuNPs and trisodium citrate

Figure S2 XRD pattern of dried powder of AuNPs

Figure S3. Optimization value of each parameter

Figure S4: Normal plot of residuals

Figure S5: LSPR spectra of probe in the presence of HER and selected interferences

Figure S6. Sensing result during $10 \mathrm{~min}$

Figure S7. AuNPs extinction coefficient calculation

Figure S8. Calibration curve in plasma after a) 1day and b) 5 days

Figure S9. The mixture of plasma, HER and nanoparticles

Figure S10. Calibration curve in fetal bovine serum 
Table S1: Design table

\begin{tabular}{ccccccc}
\hline Std & Block & Run & $\begin{array}{c}\text { Factor 1 } \\
\text { A:pH }\end{array}$ & $\begin{array}{c}\text { Factor 2 } \\
\text { B:Temp }\end{array}$ & $\begin{array}{c}\text { Factor 3 } \\
\text { C:GNPs/AgNPs }\end{array}$ & $\begin{array}{c}\text { Response 1 } \\
\text { R1 }\end{array}$ \\
\hline 6 & Block 1 & 1 & 9.5 & 35 & 0.8 & 0.005 \\
7 & Block 1 & 2 & 7.5 & 55 & 0.8 & 0.024 \\
1 & Block 1 & 3 & 7.5 & 35 & 0.4 & 0.022 \\
12 & Block 1 & 4 & 8.5 & 45 & 0.6 & 0.033 \\
11 & Block 1 & 5 & 8.5 & 45 & 0.6 & 0.029 \\
5 & Block 1 & 6 & 7.5 & 35 & 0.8 & 0.026 \\
10 & Block 1 & 7 & 8.5 & 45 & 0.6 & 0.031 \\
3 & Block 1 & 8 & 7.5 & 55 & 0.4 & 0.025 \\
2 & Block 1 & 9 & 9.5 & 35 & 0.4 & 0.018 \\
9 & Block 1 & 10 & 8.5 & 45 & 0.6 & 0.025 \\
4 & Block 1 & 11 & 9.5 & 55 & 0.4 & 0.015 \\
8 & Block 1 & 12 & 9.5 & 55 & 0.8 & 0.005 \\
18 & Block 2 & 13 & 8.5 & 45 & 0.9 & 0.004 \\
19 & Block 2 & 14 & 8.5 & 45 & 0.6 & 0.027 \\
14 & Block 2 & 15 & 10 & 45 & 0.6 & 0.004 \\
17 & Block 2 & 16 & 8.5 & 45 & 0.3 & 0.011 \\
15 & Block 2 & 17 & 8.5 & 30 & 0.6 & 0.021 \\
13 & Block 2 & 18 & 7 & 45 & 0.6 & 0.023 \\
20 & Block 2 & 19 & 8.5 & 45 & 0.6 & 0.024 \\
16 & Block 2 & 20 & 8.5 & 60 & 0.6 & 0.013 \\
\hline
\end{tabular}

Table S2: Analysis of variance (ANOVA) table

\begin{tabular}{ccccccc}
\hline Source & $\begin{array}{c}\text { Sum of } \\
\text { Squares }\end{array}$ & $\mathrm{df}$ & Mean Square & F-value & p-value & \\
\hline Block & 0.6738 & 1 & 0.6738 & & & \\
Model & 8.59 & 9 & 0.9543 & 24.71 & $<0.0001$ & Significant \\
A-pH & 3.43 & 1 & 3.43 & 88.95 & $<0.0001$ & \\
B-Temp & 0.0583 & 1 & 0.0583 & 1.51 & 0.2502 & \\
C- & 1.14 & 1 & 1.14 & 29.46 & 0.0004 & \\
GNPs/AgNPs & 0.0066 & 1 & 0.0066 & 0.1714 & 0.6886 & \\
AB & 0.7849 & 1 & 0.7849 & 20.32 & 0.0015 & \\
AC & 0.0001 & 1 & 0.0001 & 0.0021 & 0.9643 & \\
BC & 0.9054 & 1 & 0.9054 & 23.44 & 0.0009 & \\
$\mathrm{~A}^{2}$ & 0.0315 & 1 & 0.0315 & 0.8150 & 0.3902 & \\
$\mathrm{~B}^{2}$ & 2.18 & 1 & 2.18 & 56.45 & $<0.0001$ & \\
$\mathrm{C}^{2}$ & 0.3476 & 9 & 0.0386 & & & Not \\
Residual & 0.2980 & 5 & 0.0596 & 4.81 & 0.0766 & significant \\
Lack of Fit & 0.0495 & 4 & 0.0124 & & & \\
Pure Error & 9.61 & 19 & & & & \\
Cor Total & & & &
\end{tabular}



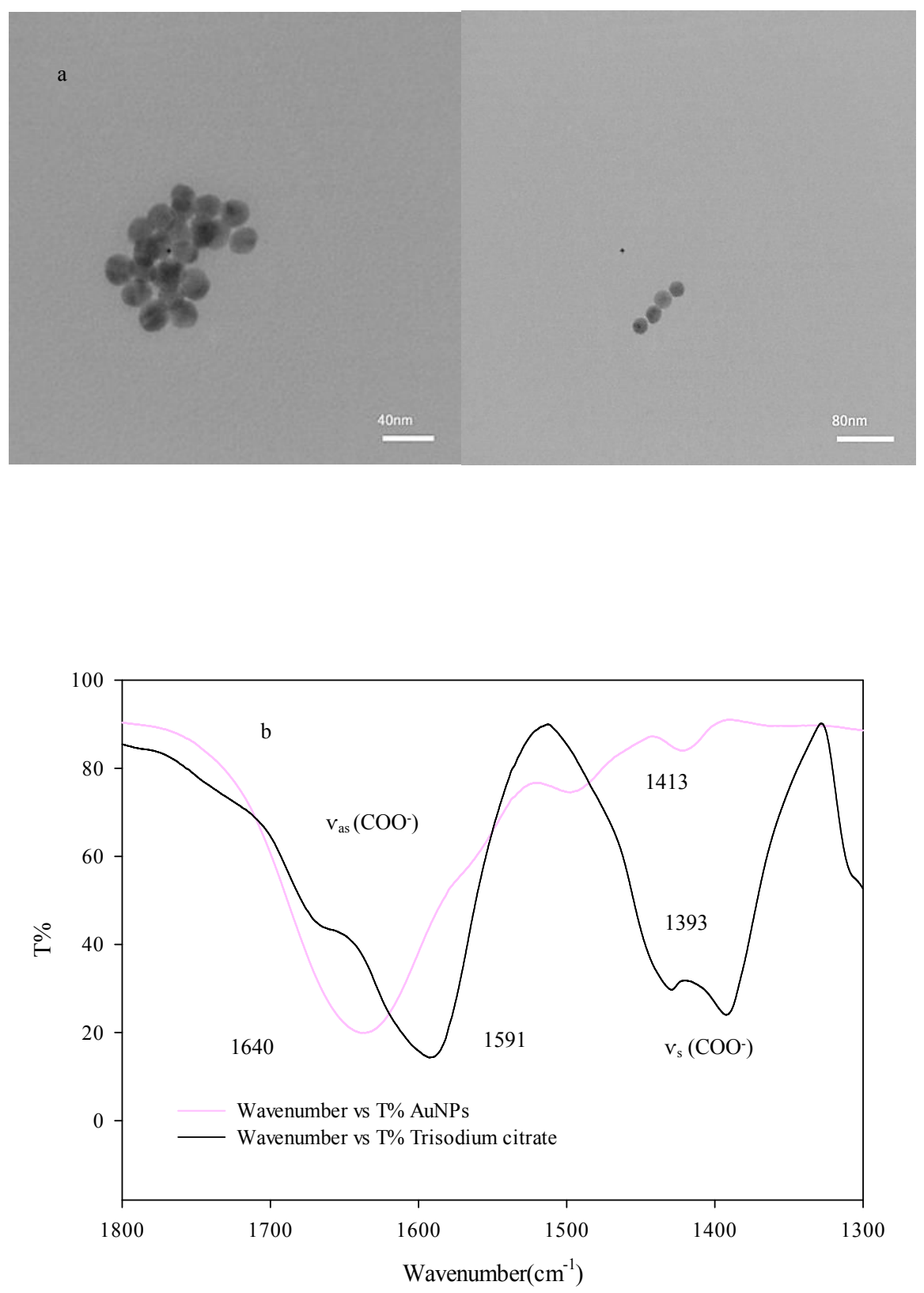

Figure S1: a) TEM images of AuNPs, b) FT-IR spectra of AuNPs and trisodium citrate 


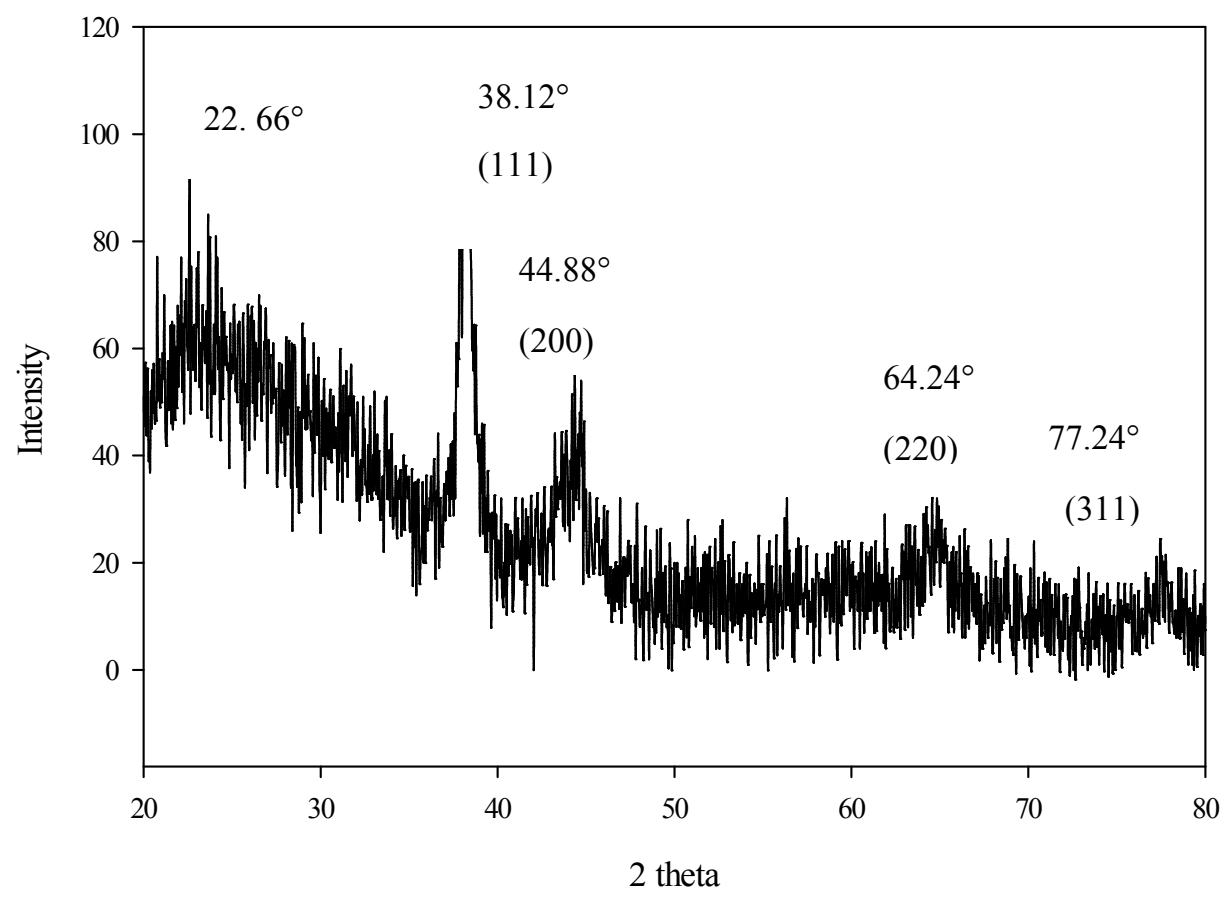

Figure S2: XRD pattern of dried powder of AuNPs 

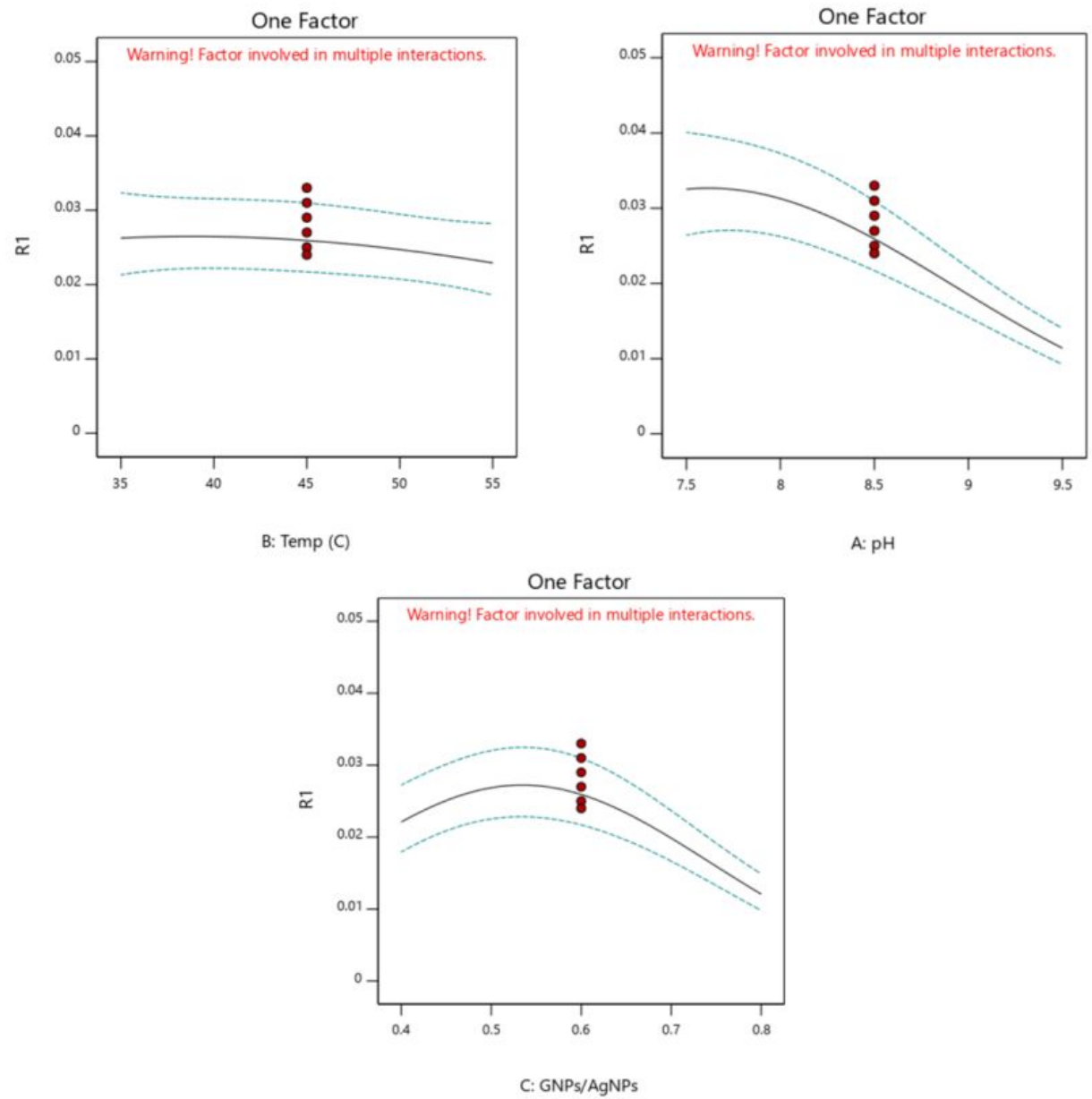

Figure S3: Optimization value of each parameter

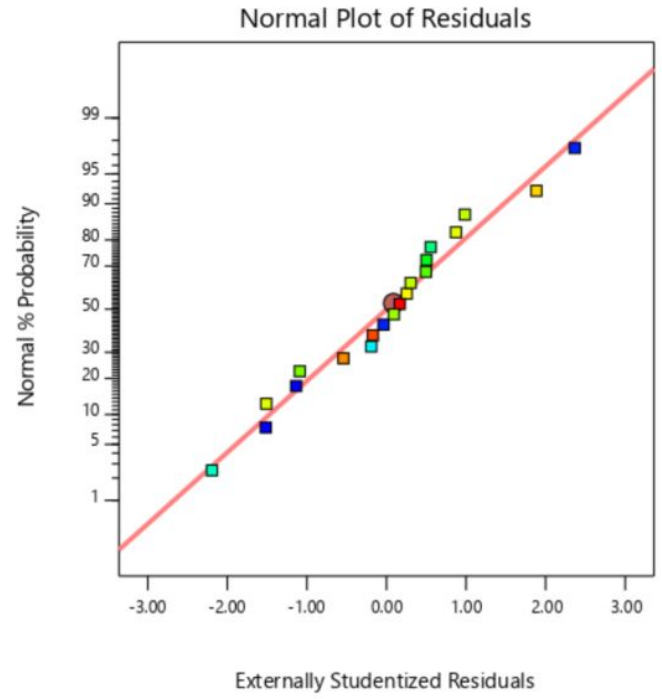

Figure S4: Normal plot of residuals 

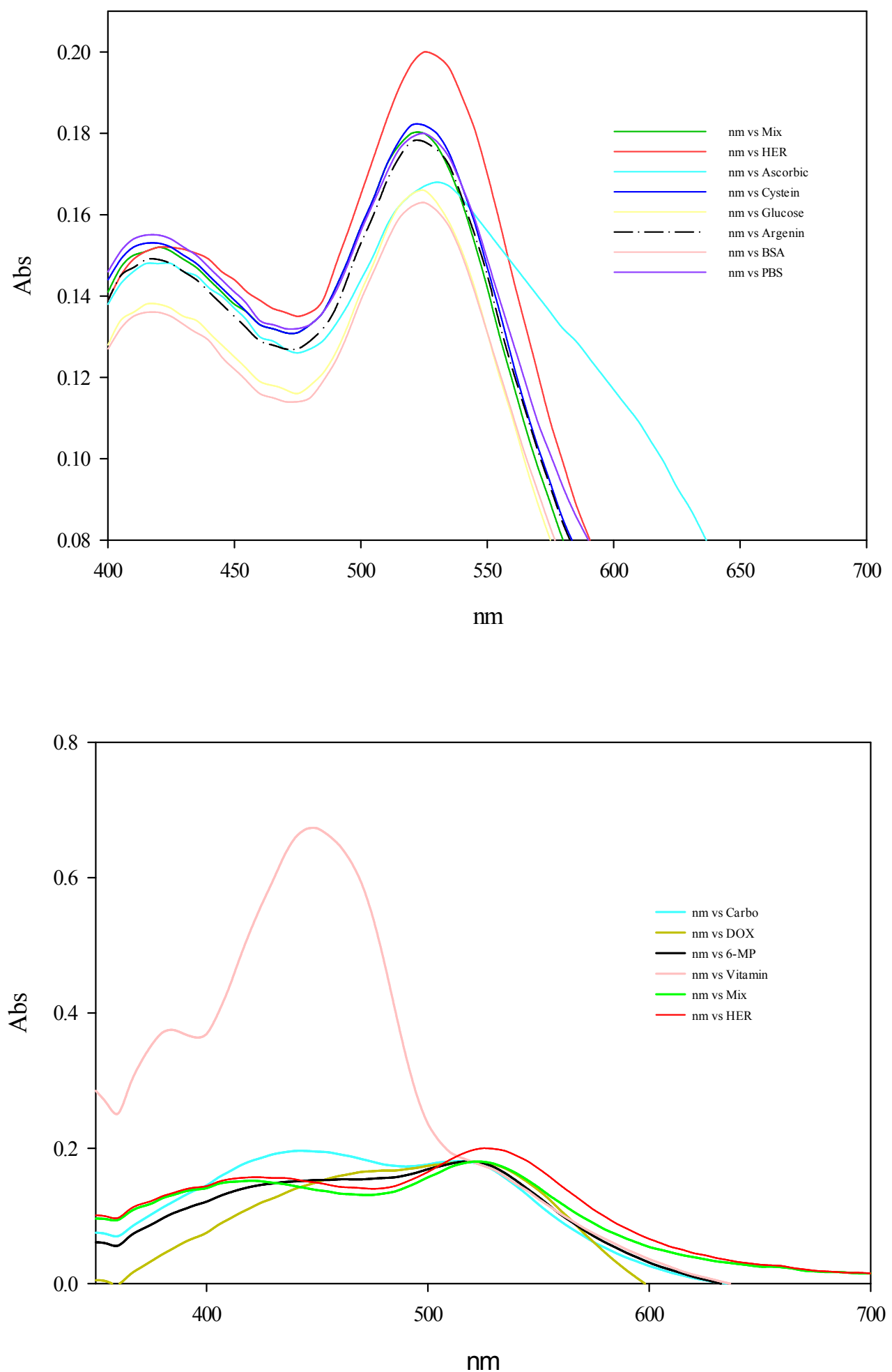

Figure S5: LSPR spectra of probe in the presence of HER and selected interferences 


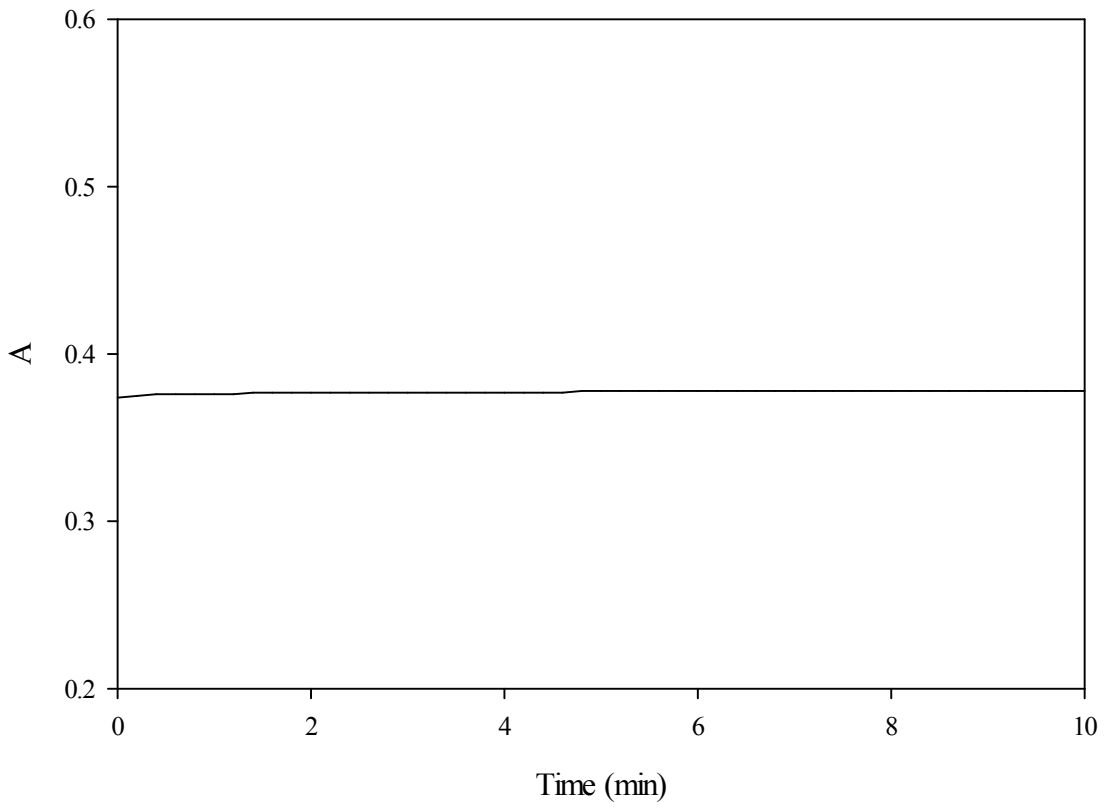

Figure S6: Sensing result during $10 \mathrm{~min}$ 


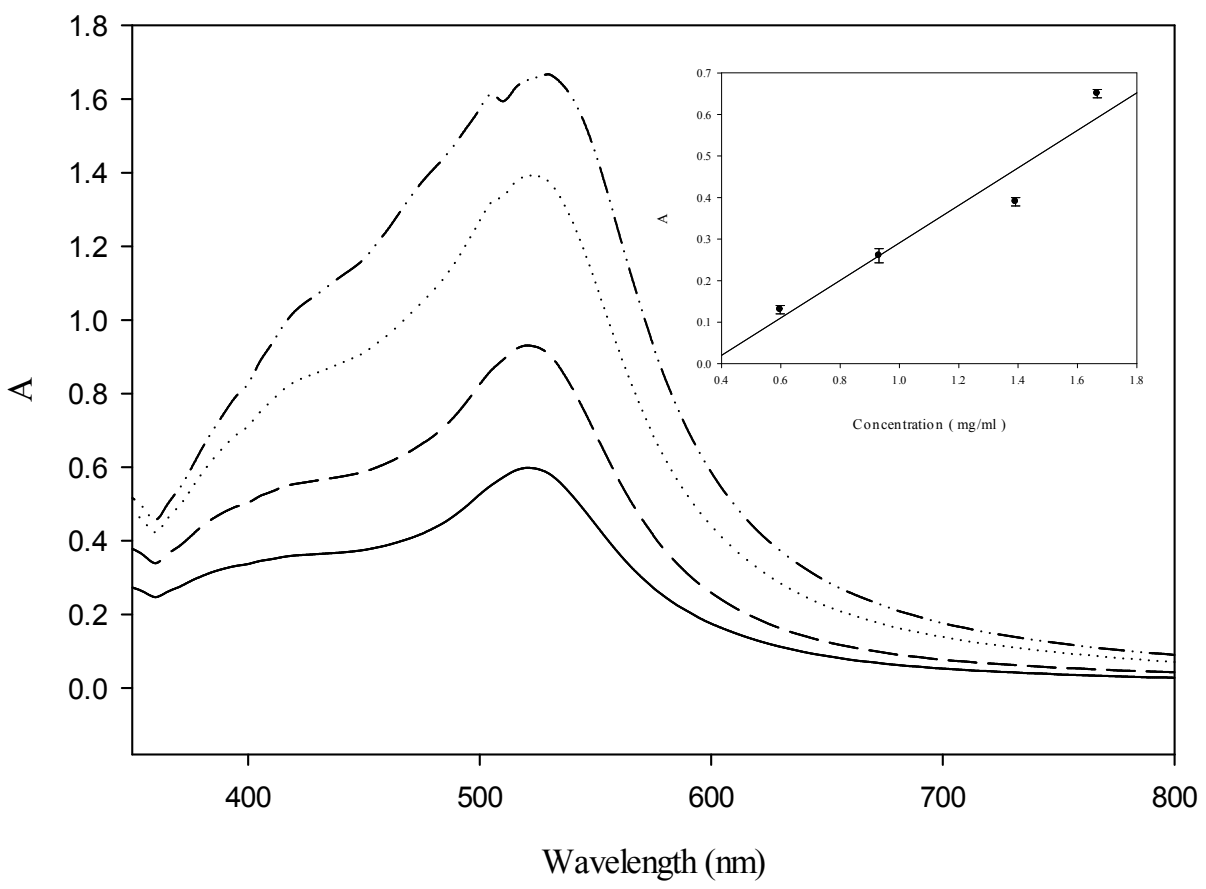

Figure S7: AuNPs extinction coefficient calculation 


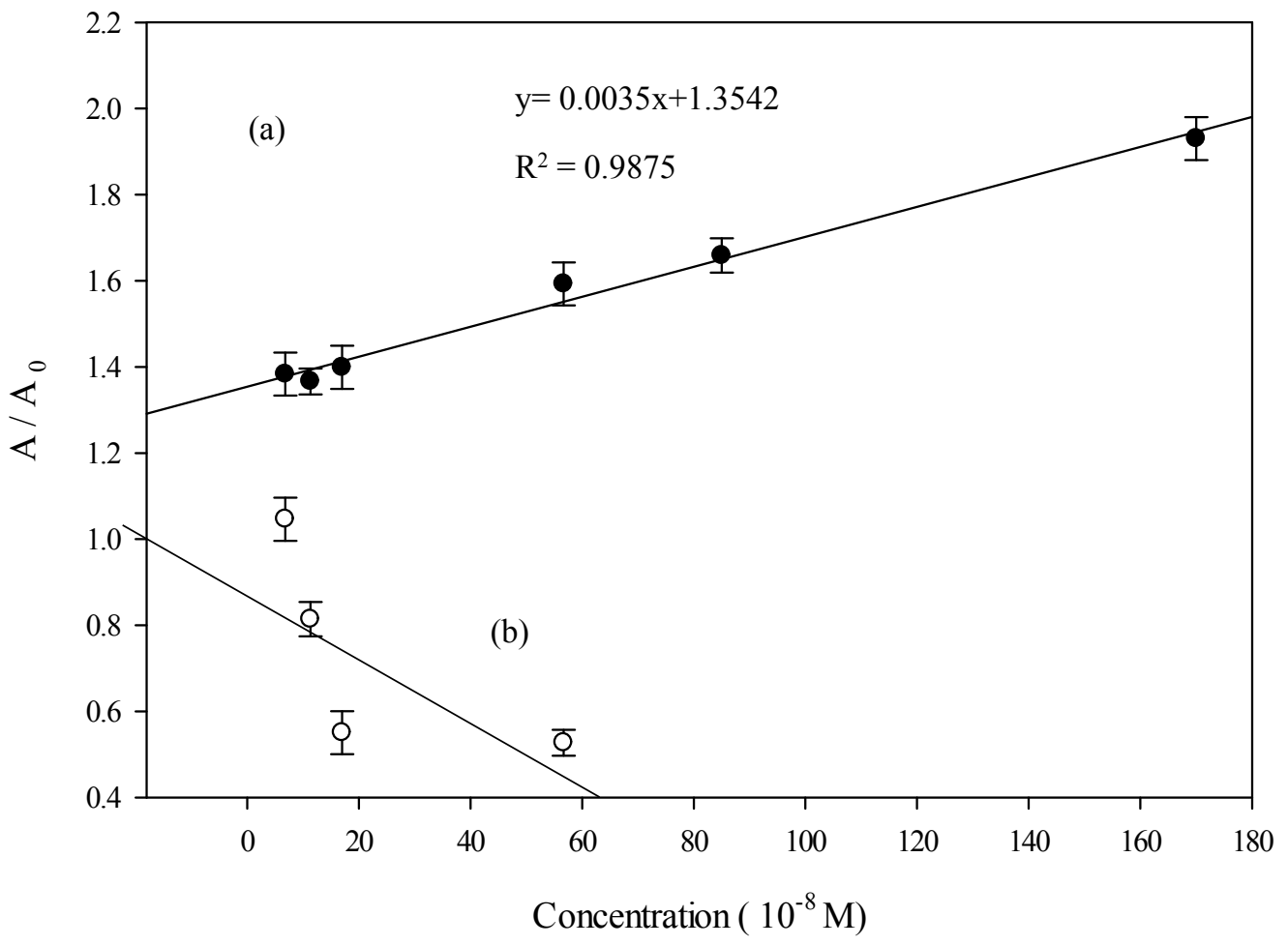

Figure S8: Calibration curve in serum after a) 1 day and b) 8 days.

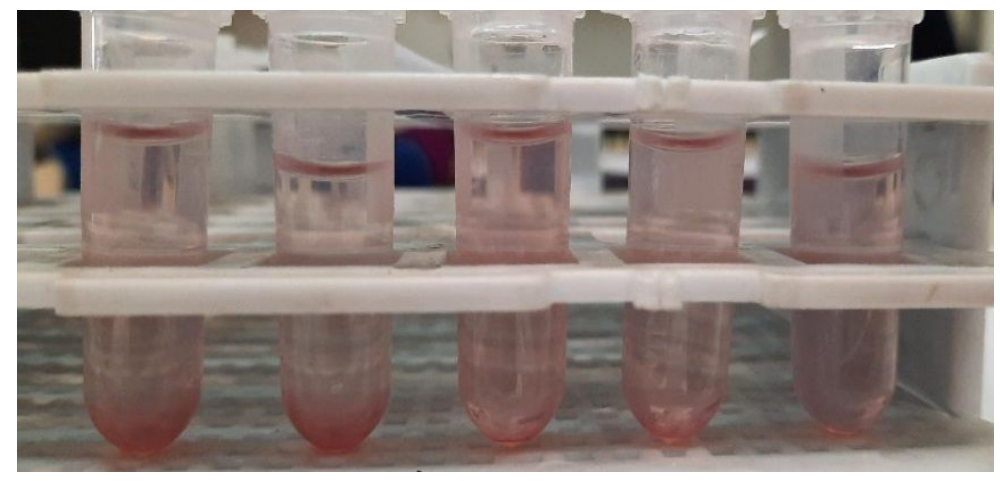

Figure S9: The mixture of plasma, HER and nanoparticles after 8 days. A portion of nanoparticle have settled which has correlation with HER concentration 


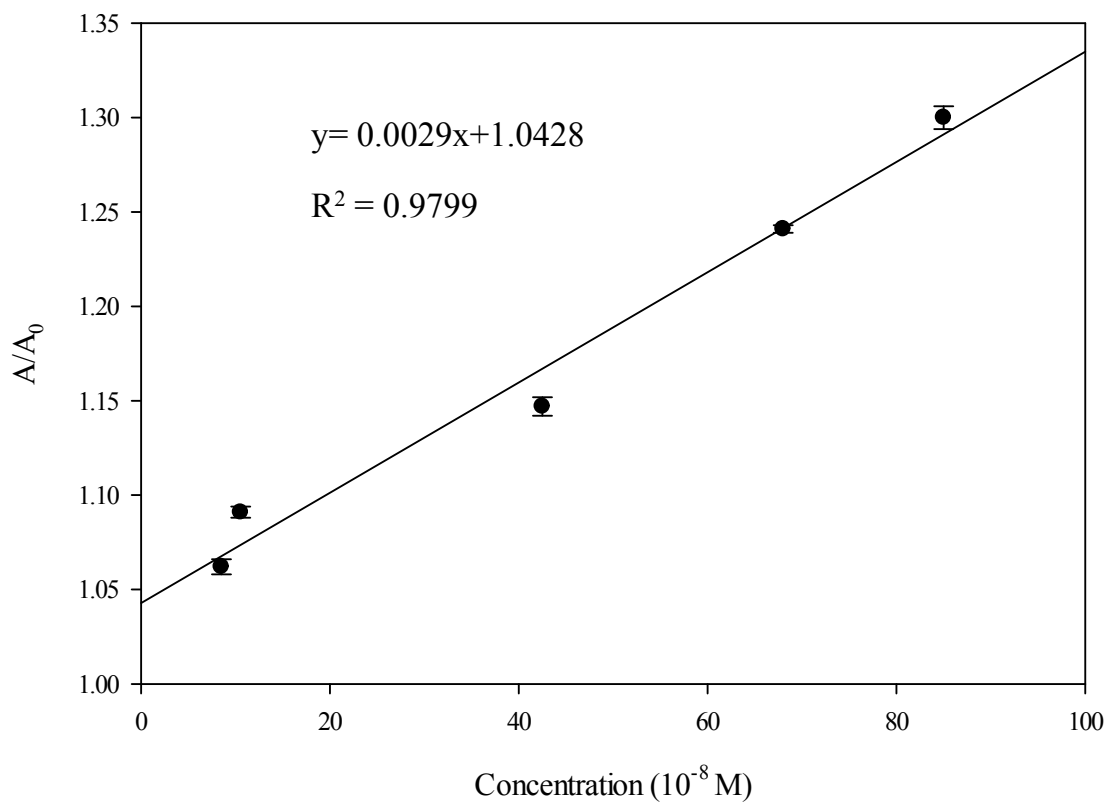

Figure S10: Calibration curve in fetal bovine serum 